\title{
Mentorship:
}

\section{Jenny Pausacker interviewed by Inez Baranay}

\author{
Alongside being recognised as a leading Australian genre and \\ children's writer, Jenny Pausacker is a leading literary mentor. \\ She has been employed as mentor to a wide variety of up-coming \\ writers around Australia. She is interviewed here by Inez Baranay, \\ acclaimed Australian writer and also sometime mentor.
}

Inez Baranay: What is a literary mentorship exactly?

Jenny Pausacker: The mentorships I've undertaken involve working with someone who has already written a draft - or a substantial portion - of a novel. My aim is for the mentee to finish and/or revise the novel to a publishable standard, though this isn't a universal aim: I know that some other mentors are more concerned about process than product, so their aim is that their mentees develop their craft and understand more about the whole process of writing.

Oddly enough - given that I've just started on my twentieth mentorship - when I first heard about the mentoring schemes, I wasn't particularly interested. Looking back, I think I got the impression that mentors were kind of like chaperones, guiding debutante writers into the literary world - or 'den mothers' - or something more caring and sharing than my natural style. But then a friend arranged to have me co-supervise his MA in Creative Writing, because he wanted to call on more of my time than he would've felt comfortable about doing if I was reading his drafts unpaid. I liked the experience of being around for the whole process, so when I was asked to take on a mentorship, I had a better sense of my interest in the area and my potential contribution.

IB: What bodies have you undertaken mentorships for? If more than one, did they operate in different ways?

JP: I've worked for the Victorian Writers' Centre (4 mentees, over 4 years); Varuna - the Writers' House (three seminars over 2 years, from which 10 mentees were selected); the Northern Territory Writers' Centre (3 mentees) and the Australian Society of Authors ( 1 mentee) along with one private mentee and mentoring the Creative Writing MA. There were some minor differences - for instance, the Victorian Writers' Centre arranges an initial meeting for the mentor and the mentee, to make sure they'll be able to work together, something that wouldn't have been practicable for the NT mentees and wasn't relevant to the Varuna mentees, since we'd already met at the seminars. Mostly, however, all the centres seem to operate on much the same principles.

IB: In practical terms, how does it operate - number and duration of meetings and so on? 
JP: Twenty hours is the standard length of a mentorship. Very roughly speaking, I usually spend half of that on face-to-face (or phone or email) discussion and the other half on one or two detailed edits of the full manuscript. The number of the discussions varies a lot. Some mentees like to talk it all through at the beginning, then go away and return with a completed manuscript. Others like to have reasonably regular contact for shorter periods of time.

IB: It seems to me that writers have acted as mentors for less-experienced (or equally experienced!) writers always, but what we are talking about here is the formalisation or institutionalisation of this relationship through schemes run by the ASA, Writers Centres, etc. Correct?

JP: I certainly started my mentoring career informally. A lot of writers complain about being offered manuscripts every time they go to a party or whatever - but I've always positively encouraged people to hand over their manuscripts for me to read. (Mind you, I've never been deluged with manuscripts, possibly because I warn people beforehand that part of the deal is total honesty, not backslapping...) I learnt a lot from giving feedback to friends and acquaintances - for example, I can vividly remember talking to one unfortunate beginner for half an hour about what she could do with her manuscript, at the end of which time, I said, 'Is there anything else you want to know?' and she just sat there, looking dazed by the information overload. I could never have taken on the job of mentoring strangers if I hadn't already practised on my mates. Conversely, I couldn't spend twenty unpaid hours on a friend's manuscript and still remain solvent, so for me there's a qualitative difference with the professional mentorship schemes, because they give me a chance to see a project through from beginning to end.

IB: Who mentored you, if anyone? Who played this role for you, or would you have wanted this when it wasn't available?

JP: My role models as a mentor are the women who supervised my MA and $\mathrm{PhD}$ theses. Neither of them was particularly interested in my topic: they both concentrated on teaching me how to write clearly and cogently. That was nonfiction writing, of course: as a fiction writer, I started to develop my own voice when I got involved with a Women's Liberation group who were writing non-sexist books for children. They gave the most ruthless, definite and passionate feedback I've ever encountered, which set my standards for feedback very high, right from the beginning.

Then the editor of my first young adult novel, accepted in 1985, gave me the kind of detailed constructive criticism that's relatively rare now. And these days I swap manuscripts with a group of my peers, something that's become a fairly standard practice among professional writers, after publishing houses had to cut their budgets in the downsizing days of the late 80 s and 90 s, thereby cutting down on the amount of editing time that could be allotted to any specific novel.

IB: Is this swapping manuscripts a substitute for the editor of past days? Would you not be doing it if we still had editors? Or doing it differently or less? I know you as someone who's read my own work-in-progress and so I know how marvellously you do something I think you once called defending the book against the writer. Is that what you look for from these peer readers? Just whatever response they make, or do you ask for comment on any specific thing?

JP: Me, I like to get a range of opinions on anything I've written, so I'd still want to have a swapping system, even if all my publishers doubled their editing budgets overnight. But I think the swapping system became more crucial, because of the budget cuts - although I should add that different publishers allot different proportions of their budgets to editing. I changed publishers at one point after I was 
given a first-time editor. (Yes, of course, all editors have to start somewhere, but a first-time editor isn't likely to have developed much of a feel for the sort of problems a twenty-years-in-the-business writer wants to be alerted to.) My current publisher is way more of a safety net: I get two experienced readers' opinions from them, as well as my peer readers. And I guess I want the same thing from all of them - i.e. to be told when something doesn't work for them. If the same thing doesn't work for two of them, I change it, no matter how attached to it I am...

IB: How is a mentor chosen in these schemes?

JP: The writers' centres choose the mentees - and, um, I've never asked any of them how they came to choose me.

IB: How are the mentees chosen?

JP: I've always selected my own mentees, by reading through all the manuscripts submitted for the scheme. Sometimes the people at the Writers' Centres also read the submissions and discuss them with me; sometimes they leave it all up to me. There are other schemes where the centre selects a shortlist for the mentor - but I think I'd always want to see everything that had been submitted.

IB: Have you found that other mentors have a different take on it?

JP: I haven't talked to many other mentors - at this point, it's an even more isolated occupation than writing, although there are some moves in progress to bring mentors together, so we can discuss the issues involved. However, I have heard one mentor describe mentoring as an intimate relationship, where the mentor and the mentee become friends. That made me uncomfortable, because I don't see mentoring as anywhere near that personal, so I started to wonder about the whole question of boundaries between mentors and mentees - the sort of thing that was discussed in the Jane Gallop article you recommended to me on 'The Perils of Mentorship'.

I'm still not entirely sure where I stand on this but I guess my position is a slightly lateral one, in that I consider myself to have a close relationship with the text, rather than the mentee...who also, of course, has a close relationship with the text $<$ grin $>$. So mainly I work with the mentees - but if it comes to a choice, I choose what's best for the manuscript, rather than what's best for the person writing it, although I'd understand if the mentee said, 'No, I don't want to push myself that far.' (But none of them ever have, as yet.) I also found it interesting that the mentor who aimed at having an intimate relationship with the writer, as opposed to the writing, met the mentees in coffee shops, whereas I see them in my home, if possible, because I can jump up and fetch any books that we start talking about - and because I think it's vaguely useful for them to see how a full-time writer lives. So, clearly, different mentors have different definitions of intimacy.

IB: What are your responsibilities and obligations to the mentees?

JP: Ooh, good question. I think it's my responsibility to respond as quickly as possible to any requests for information, backup, or the reading of drafts. Sure, once the writers start sending their manuscripts out to publishers, they'll have to learn how to wait - but I still remember how vulnerable I felt in my own beginner days, when I'd given a manuscript to someone, so I think speedy feedback is part of my responsibilities. I also think it's my responsibility to check and make sure the mentee understands the feedback and, in general, to make the ground rules of the mentorship clear. And I think my main responsibility is that the mentee should end up more confident than when they started. 
IB: That's interesting. It is true that a constructive reading - a reader who understands what you're doing, supports it and offers useful comments on how to achieve what you're going for - has the effect of creating confidence, if the lack of it came from wondering if you are even writing what you think you're writing. A good reader of work in progress can explain to the writer what they're doing. Is that what you mean? Does a writer gain this confidence with experience?

JP: Well, a constructive reading probably helps - but I was thinking more about the side of mentoring that goes beyond the text, into areas like the writer's motivation for writing, how they feel about their private pastime going public, how they're going to deal with editors, readers, speaking to groups and all the associated business of a writer's life. One of the big milestones is starting to feel like A Writer, rather than someone who writes sometimes. I took part in a survey of women writers at one stage which established that most of us started to feel like A Writer at the point where we wrote 'writer' under 'occupation' on our tax forms - but I think a mentorship can produce the same effect. So I guess an alternate way of saying 'confidence' would be 'taking yourself seriously as a writer'. Some of my mentees arrive serious: with others, it's something we work on.

IB: Going back to the previous point, can you tell me more about the kind of feedback you're likely to give? And what are your ground rules?

JP: My basic ground rules are (a) that the mentee sets the agenda and (b) that, conversely, I give very specific feedback. In my experience, general feedback is confusing. (Example: 'make this more dramatic' - as if any writer deliberately withholds potential drama.) So I warn mentees from the start that I'm going to tell them what I'd do with areas that I see as problematic - and that they're entitled either to take my suggestions, if they fit, or else use them to generate their own solutions. ('No, I wouldn't do that in Jenny's way. I'd do it this way.') So far, all my mentees have been appropriately stroppy: I've never seen any evidence that they were adopting all my suggestions, simply because a mentor made them. One mentee said, after I'd done a detailed edit on a sample chapter, 'But this is too easy! You've done it all for me.' I said sharkily, 'And now you have to do the same thing for the rest of the novel': and she decided it wasn't too easy, after all...

As for the kind of feedback I give - um, it depends on the mentee and the manuscript. Sometimes I give a lot of feedback on style; sometimes almost none. The same goes for narrative construction, characters' motivations, the writers' own self-confidence or audience reception. Sorry, it's hard to be more specific without describing an individual mentorship in detail - and that'd be breaking confidentiality: I don't discuss my mentees, any more than a therapist discusses their clients $<$ grin $>$.

IB: What are the responsibilities or obligations of the mentees?

JP: To put words on paper! Seriously, I don't regard it as my responsibility to motivate the mentees, lay down deadlines or timelines or nag mentees into producing. They set the agenda: I'm there to help them do what they want to do. Being a writer involves a pretty high degree of self-discipline. I don't feel I'd be doing the mentees any favours if I did the disciplining for them - and so far, at any rate, I haven't needed to: they've all been very highly motivated.

IB: If you have a choice in who you mentor, how do you choose that person? What do you look for, what do you avoid?

JP: Hmm. I don't have a formulated checklist; I basically work on instinct - and I'd justify that by saying that a checklist could result in ignoring manuscripts that didn't meet the criteria but had their own kind of promise or selecting work that looked good in point form but lacked the requisite energy. I guess I'm looking for 
strong central premises - or unusual and engaging characters - or a flair for language - or writers who already show, rather than tell. But most of all, I look for commitment, the sense that the writer's hungry to tell that particular story. There's nothing that I specifically avoid but there are manuscripts that don't make it through my first cull, either because the writer hasn't demonstrated any feel for language (something that, in my opinion, can't be taught) or because the manuscript is too derivative: okay, we all draw on a common body of themes but I don't see it as my business to help people write books that have already been written.

IB: In some mentorship schemes, applicants submit, along with their work, a statement about it, including what they want from the mentorship, and some kind of self-assessment. Have you found this useful? (I wonder if some people can't be mentored, including those who will write the way they are already writing no matter what, and a statement of this kind can tell you that.)

JP: $<$ blush $>$ I scan the self-assessment but I don't take much notice of it. I rely much more on the work itself - in other words, I'm more concerned that people can walk the walk than that they can talk the talk.

\section{IB: Have you made any mistakes as mentor?}

JP: During a seminar explaining the mentorship scheme at one of the writers' centres, I mentioned that I begin the selection process by discarding manuscripts that don't need a mentor, which gave some of the audience the impression that we were letting publishable writers think they weren't even worth a mentorship. I had to explain that as a mentor of young adult fiction, I see a lot of genre fiction that fits the genre okay but isn't worth developing further, which is more denigratory than I like to be in an introductory session. Then again, that raised an important issue. Mentorship schemes should indeed have some sort of procedure for telling applicants that their work is already of publishable standard - although 'publishable standard' isn't a guarantee of publication, so that's not quite as simple as it sounds.

IB: I remember a mentorship I undertook at the experimental stage of these schemes for a new writer whose novel in progress was autobiographical. The biggest problem we had was that its material took her up to the present day, and as her life and her take on her life kept changing, she could not commit to what the basic material of her novel was, and kept wanting to take its scope into the newest phase of her life. At the time you remarked, if I remember rightly, that autobiographical novels were unsuitable; have I got that right?

JP: The writers' centres I've worked with have told me that other mentors had similar problems with autobiographical writing, sometimes because the writer was too close to the work and got defensive about suggested changes. As far as I know, I've only once worked on a directly autobiographical novel and in that case, the writer wanted to move away from memoir, towards a novel that was more independent of their own experience, so there wasn't any conflict between their intentions and my area of expertise - i.e. as a mentor, rather than a therapist or whatever.

IB: Other mentorships I have done have been with writers who have some kind of 'track record': a proven ability to complete and publish work... How experienced should a new writer be to qualify for mentoring?

JP: I haven't found experience to be particularly relevant. Some of my mentees are working on their first extended piece of writing: if it reads well, that's fine by me. On the other hand, some applicants include quite extensive CVs - stories that won competitions and the like - but don't show the same originality in the manuscript they've submitted. I always make my judgement on the basis of the manuscript itself, not on the basis of the writer's track record. 
IB: How important is it that the mentees' work should be intended for publication, and/or in your view publishable? If important, why? - is it only to 'prove' the success of the scheme in some way?

JP: As I said above, a publishable manuscript is one of my aims. I don't expect to achieve this every time but I don't see any point in working with someone, unless they're trying to communicate - that is, unless they're writing for readers. That's not a value judgement: I can definitely understand why a writer might spend time experimenting, with no particular readers or outlets in mind. However, I wouldn't know how to assess that kind of writing - in fact, I'd question whether my assessment would be of any benefit: basically, I reckon the writers themselves would have a clearer sense than anyone else of whether their experiments are working for them.

What I can offer is an informed reading of the text and suggestions for how to make it go deeper and/or be more compelling/centred/clearly expressed. As a mentor, I call on everything I've learned as a writer - but since I essentially come to the manuscript as a reader, one of my preconditions for mentorship is that the mentee wants readers, which in a market economy means that they want to sell their book to a publisher.

IB: I think of my autobiographical first-time unpublished new novelist - the potentially never-ending project. The mentorship might have been of great value to that person in their understanding of how a writer works or even as an exercise in personal development. How do we measure the success of any particular mentorship?

JP: Well, the bottom line is that, if the mentee gets something out of it, then the mentorship has been successful. As a mentor, I feel as though the mentorship has worked if the mentee finishes the project: completing a long project, as compared to working on it every now and then, is a milestone for any writer. Publication is good $<$ grin $>$ but I also feel a mentorship has worked if, for example, the mentee signs up for a writing course that they'd been considering or makes more time in their life for regular writing.

IB: So the mentorship can work as a kind of turning-point at which the new writer makes a commitment to the writing life that might have been more of a flirtation till then? Can a mentorship be seen as successful in a different way if the new writer discovers that they cannot after all make that commitment? Has that ever happened?

JP: I haven't had any mentees so far who didn't finish the nominated project. As for whether finishing the project made them decide that the game wasn't worth the candle, that could only be ascertained by follow up, which would be better done by the Writers' Centres than by me. As I think I've said before, I don't nag - and asking 'Have you sent the book to lots of publishers? Have you started your next book?' sounds like nagging to me. People's lives often take over for a while, on their way to full-time writing. I've had mentees who've been temporarily derailed by personal griefs and difficulties, work promotions, discouragement after rejections and the like...but I've been derailed in similar ways myself and I'm still writing, so I never make any assumptions about what's going to happen next with my mentees.

IB: What's the difference between mentoring and editing?

JP: As a mentor, I work with what the writer wants to do. I might read a manuscript, find one aspect of it unsatisfactory and suggest scrapping it - but if it turns out to be part of the writer's main reason for writing the book, I turn round and start figuring out ways to make that aspect more effective. Editors, conversely, are preparing a book for publication, so it's their business to suggest ways to make 
it more accessible to a range of readers and more marketable, which may or may not fit with the writers' intentions.

However, I should add that I checked this theory with my current editor, who said, 'True...but as an editor, I do a lot of mentoring' - and I had to agree that, as a mentor, I also do a lot of editing < grin>.

IB: And what's the difference between mentoring and teaching writing?

JP: Teaching writing - in my opinion, okay? - means dealing in generalisations. Since I don't like generalisations at the best of times and, at the worst, see them as actively harmful, I don't teach writing... which obviously limits my ability to comment. However, I've had a fair few friends and mentees who started to believe they couldn't write, because they didn't write the way their teacher did. As a mentor, I'm making specific comments about a specific manuscript. Since I start from the medico's principle, 'first, do no harm,' I feel that the potential for damage in mentoring is considerably less.

IB: Is mentoring different from postgraduate supervision?

JP: I'm not sure. You tell me...

IB: Well, you did take on the supervision of a creative writing MA, right? So did you do anything differently there, see your role there differently?

JP: No, I wasn't the supervisor, so much as the back up. My friend - the one who wanted to be able to ask me for more readings than he felt friendship covered - got me a consultant's fee: I covered most of the creative stuff and the supervisor made sure it was in line with the college's rules and regulations. So basically I just did the same thing I do as a mentor.

IB: It seems to me the difference is that in mentorships the aim is a publishable manuscript, and in supervision it's a manuscript that will get passed by examiners not quite the same thing perhaps! And the supervision relationship goes on much longer, though there will most likely be more and longer periods without contact.

JP: Yes, paradoxically, creative writing courses are part of the reason why we need mentorship schemes. I've already talked about the effect of the downsizing in the publishing industry but, as a result of the proliferation of writing courses, editors also have way more manuscripts landing on their desks than in the 70s, when I started out, so [publishers are] trying to do more with less. I've heard creative writing lecturers say they set students the task of submitting a manuscript to a publisher, to give them practice with submissions, even when the lecturer doesn't consider the manuscript publishable. To me, that sounds unfair to both the students and the publishers. My Creative Writing MA mate was definitely aiming for publication - and it worked: his book's still selling well.

IB: Would all writers benefit from mentoring or only some?

JP: I assume that the writers who don't apply for mentoring schemes have made a self-assessment that they wouldn't benefit from having a mentor - although I've begun to realise that a lot of writers haven't heard much about the schemes or don't really understand the concept of mentoring, so I may have to revise this assumption. However, one of the ways in which I keep myself honest as a mentor is through my hobby of fanfiction (i.e. zine or online communities who write their own stories based on existing texts). This is an utterly personal form of writing, where the first audience is oneself and the widest audience is a closed community of like-minded fans. While the writers in my fandom are definitely interested in craft matters, almost all of them are much more picky about the feedback I give 
them than my mentees are. They're writing what they want to write and they don't intend to change it for anyone. So I figure there must be plenty of mainstream writers who feel the same way, which helps me keep my mentoring in perspective that is, it works because the mentees want it to work, as much as anything...

IB: What part does gender play in this?

JP: I read more applications from women than men, though this may reflect the area I work in: I suspect that a lot more women than men write for younger readers.

IB: Would all writers be good at mentoring or are there specific qualifications - and if so, what?

JP: Some writers feel that, if they became too self-conscious about what they're doing, they'd lose the ability to do it. I can't imagine that this approach to writing would combine well with mentoring. I've got an academic background, I do a lot of reviewing and I've spent a lot of time giving feedback to friends and acquaintances, all of which means I've had several decades of putting my reactions to what I read into words: which is the basic requirement of mentoring.

However, having said this, I also think that mentoring by a writer would have to be qualitatively different than mentoring by an experienced reader who doesn't write themselves. As well as giving specific feedback, I spend a fair bit of time talking about the points at which I've encountered similar problems in my own writing. If I had ten dollars for every time a mentee's said, 'Oh, so I'm not the only person who has trouble with that...' I could probably take on an extra mentee gratis.

\section{IB: When does mentoring stop?}

JP: Basically, in my view, the mentoring stops at the end of the twenty hours - but since I want to know what happens to the finished product, I give all my mentees an imaginary voucher that entitles them to two extra bits of assistance later on - e.g. checking rejection letters or readers' reports from publishers. And some of my mentees keep in touch, while others don't, although they've always phoned to tell me when the book's accepted, won an award, formed the basis of another successful application for a grant or resdiency or whatever.

IB: One thing I want to raise, although you have touched on it, is the question - and this comes up with editors too - about who 'really' authored a given book. I wonder where mentorship/editing verges on collaboration....

JP: Good point. I'm opposed in principle to that kind of covert collaboration - like, how does it help the mentee? - which is why I only do sample detailed edits: that way, it's obvious if chapter one is neat and smooth and the rest is ungrammatical and erratic. And while I make concrete suggestions about the structure of the sections they've written and suggest possible directions for the rest of the novel, the mentees have to put that into practice - and they can't, if they haven't internalised my advice. So I don't see myself as collaborating - but I can see how it might become a temptation, if mentors were to be judged by results such as how many of their mentees get published.

IB: Finally, what concluding evaluation would you make? How do you feel overall about the mentoring process?

JP: I started to be offered mentoring work at a point where I was radically revising my own writing practice. It was perfect timing: in one way, I feel as though I'm as much of a beginner as my mentees and I've definitely learned a lot from the whole process. But with 60 published books under my belt, I'm not the same kind of beginner as the mentees $<$ grin $>$. An Aboriginal writer pointed out to me a while 
back that in her terms I was an elder, with the responsibilities that entails. I saw that as an interesting challenge, so it was good to have the opportunity to pass on some of what I know, through the mentorship schemes.

And do mentorships work? Well, out of the ten novels I've mentored to completion so far, five have been published or accepted for publication, including a Vogel award winner, and I know that at least three of the other five writers have already started or, in some cases, finished their next novels. That's nice - but it's not the whole story. In a way, I reckon the best part of mentorships is that, if the mentor's honest with them, emerging writers get some insight into the writing life. I suspect I wouldn't have signed up for a writing course, when I was starting out, because I'm not very good at being told what to do. But a preview of what it's like to be a writer...oh yes, I could certainly have used that.

The TEXT Interview for October 2002 was sponsored by the School of Arts, Griffith University.

Jenny Pausacker has edited two anthologies and published over sixty books for children and young adults, including What Are Ya? (Angus and Robertson Writers Fellowship) and Mr Enigmatic (NSW Premier's Prize for Children's Fiction). She has a PhD in children's literature, reviews for the Australian and is currently working with three mentorship schemes.

Inez Baranay has published six books of fiction and nonfiction. She is completing her dissertation for a PhD at Griffith University, where she teaches Creative Writing on a sessional basis. <www.ozemail.com.au/ inezb $>$

\section{TEXT}

Vol 6 No 2 October 2002

http://www.griffith.edu.au/school/art/text/

Editors: Nigel Krauth \& Tess Brady

Text@mailbox.gu.edu.au 